\title{
Research Paper: Reliability and Validity of the Persian Version of Reasons for Death Fear Scale
}

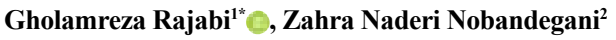

1. Department of Counseling, Faculty of Education and Psychology, Shahid Chamran University of Ahvaz, Ahvaz, Iran. 2. Department of Psychology, Faculty of Education and Psychology, Yazd University, Yazd, Iran.

\begin{tabular}{|l|l|}
\hline $\begin{array}{c}\text { Use your device to scan } \\
\text { and read the article online }\end{array}$ & $\begin{array}{l}\text { Fear Scale. Journal of Practice in Clinical Psychology, 8(1), 9-16. https://doi.org/10.32598/jpcp.8.1.9 } \\
\text { dej"https://doi.org/10.32598/jpcp.8.1.9 }\end{array}$ \\
\hline
\end{tabular}

\section{() 0}

Article info:

Received: 03 Jun 2019

Accepted: 23 Oct 2019

Available Online: 01 Jan 2020

Keywords:

Death, Reason for death, Reliability, Validity

\section{ABSTRACT}

Objective: This study is an attempt to investigate the validity and reliability of the Persian version of the Reasons for Death Fear Scale among men and women attending in religious rituals of Mosques in Shiraz, Iran.

Methods: The sample consisted of 157 participants attending in religious rituals of Mosques in Shiraz, who were selected by a convenience sampling method after obtaining informed consent. They completed the Reasons for Death Fear Scale.

Results: The results of exploratory factor analysis on RDFS identified 4 factors. Cronbach's $\alpha$ coefficients was 0.86 for the entire of measure (18 items), with alphas ranging from 0.70 to 0.81 for the individual factors. The indices of convergent and divergent validity for this scale were all significant $(\mathrm{P}<0.001)$.

Conclusion: Given the validity and reliability of the Reasons for Death Fear Scale, this scale can be used in clinical settings and research studies.

\section{* Corresponding Author:}

Gholamreza Rajabi, PhD.

Address: Department of Counseling, Faculty of Education and Psychology, Shahid Chamran University of Ahvaz, Ahvaz, Iran.

Tel: +98 (61) 33333911

E-mail: rajabireza@scu.ac.ir 


\section{Highlights}

- Investigating on the psychometric properties of the Persian version of sexual self-efficacy scale-female functioning

- The results of exploratory factor analysis on RDFS identified 4 factors.

\section{Plain Language Summary}

This study is an attempt to investigate the validity and reliability of the Persian version of the Reasons for Death Fear Scale among men and women attending in religious rituals of Mosques in Shiraz, Iran. The sample consisted of 157 participants attending in religious rituals of Mosques in Shiraz, who were selected by a convenience sampling method after obtaining informed consent. They completed the Reasons for Death Fear Scale. Given the validity and reliability of the Reasons for Death Fear Scale, this scale can be used in clinical settings and research studies.

\section{Introduction}

Fear of death is a global phenomenon, and the main subject in thanatology, in every part of the world you would find many people who are afraid of dying. There is a clear reason for the fear of death: Death is the strangest phenomenon in the world, 1 surrounded by numerous unknown variables, and it is the inevitable part of the human life (Dezutter, Luyckx, \& Hutsebaut, 2009). Anthropologist Becker (1973) argued that "the idea of death, the fear of it, haunts the human animal like nothing else. Humans are social beings, and it is our interactions with other humans that complete our existence and give our lives meaning" (Moore \& Williamson, 2003). Paul (2012) describes the fear of death as stemming from two beliefs: 'When we die, we disappear' and 'when we die we will be punished for our sins'. Kastenbaum and Aisenberg (1972) identified six specific death-related fears from a self-other orientation that include a fear of dying, a fear about what might happen following death, and a fear of extinction. Choron (1974) distinguished three varieties of death fear: 1 . What happens after death; 2. Fear of dying; and 3. Fear of ceasing to be.

Hoelter and Hoelter (1978) distinguish eight dimensions of the death fear: fear of the dying process, fear of premature death, fear for significant others, phobic fear of death, fear of being destroyed, fear of the body after death, fear of the unknown, and fear of the dead. Similarly, Florian and Mikulincer (1993) identified three components of the death fear: intrapersonal components related to the impact of death on the mind and the body, which include fears of loss of fulfillment of personal goals and fear of the body's annihilation; an interper- sonal component that is related to the effect of death on interpersonal relationships; and a transpersonal component that concerns with fears about the transcendental self, composed of fears about the hereafter and punishment after death.

Wong (2008) presented different aspects regarding the meaning of death fears; these aspects are rooted death anxiety. The 10 meanings he proposed were finality, uncertainty, amihilitation, ultimate lose, life flow loneliness, and judgment and retribution. Compbellm (2013) stated the following reasons for death fear: the unknown loneliness and anxiety from tolerating the death experience; loss of family and friends; the loss of self-control of bodily functions; possibility of suffering; and the failure to achieve one's life goals.

Also, various studies consider variables that are related to death such as death anxiety (Abdl-khalek \& TomasSabado, 2005; Chen, Benk, \& Lewis, 2006; Rajabi \& Bahrani, 2002; Templer, 1970; death obsession (Abdelkhalek, 1998; Abdel-khalek, 2002b; Abdel-khalek, AlArja, \& Abdalla, 2006; Maltby \& Day, 2000; Rajabi, 2009), death depression (Almostadi, 2012; Alvarado, Templer, Bresler, \& Thomas-Dobson, 1995; Rajabi, Begdeli, \& Naderi Nobandegani, 2015), death distress (Abdl-khalek, 2004; Abdl-khalek, 2005; Al-Sabwah \& Abdel-khalek, 2005-2006), attitude toward death (Abu Hasheesh, Al-Sayed AboZeid, Goda El-Zaid, \& Alhujaili, 2013; Dezutter, Luyckx, \& Hutsebaut, 2009; Neimeyer, Wittkowski, \& Moser, 2004).

Since the late 1950s, many studies have been undertaken to determine if religiosity is associated with fear of death (Ellis \& Wahab, 2013). Meanwhile, because many 
psychological theories have considered human concern about death and dying as related with religion, it seems that there is a specific relationship between individuals' attitude toward the religion and their view on the death problem (Dezutter, Luyckx, \& Hutsebaut, 2009). Moreover, according to the results of the studies, there may be a relationship between death fear-related variables such as death anxiety and depression and the religion (Maltby $\&$ Day, 2002). The results of Power and Smith's research (2008) revealed that the more religious participants had higher fear of the dead, fear of being destroyed, and fear of conscious death, whereas participants with lower religious conviction were more fearful of the unknown.

First time, Abdel-khalek (2002A) developed a scale to investigate the Reasons for Death Fear among Muslims. The sample consisted of 307 university undergraduate students recruited from Egypt, Kuwait, Lebanon, and Saudi Arabia. After investigating the responses of these participants, the items that were ambiguous, repeated and irrelevant were omitted and rests of the items were edited. Afterwards, the preliminary version of the scale was forwarded to four staff members in the Psychology Department of Kuwait University to judge its suitability. Then, the scale was administered to 255 male and female undergraduate students. In this stage, a number of items were omitted again. The final form of the scale consisted of 18 items. Abdel-Khalek identified four factors: fear of pain and punishment, losing worldly involvement, consequences of religious, and failures, being parted from loved ones that are among major factors of death fear for Arabic or Muslim college students.

Although, in Iran, various studies (Rajabi et al., 2015; Rajabi \& Bahrani, 2002; Roshdieh, Templer, \& Cannon, 1999) have been done on Iranian sample about death, but no study directly considered the reasons of death in Muslims society of Iran. In this study, therefore, our target is study of reliability and validity of the reasons for fear death in Iranian samples. This study expands upon this previous research and aims to answer the following questions: 1. What is the optimal factor structure for the Reasons for Death Fear Scale, as determined by exploratory factor analysis?; 2 . Does the Persian version of the Reasons for Death Fear Scale have an appropriate convergent, divergent validity and reliability?

\section{Methods}

The present study was psychometric of methodological type. The sample of this study using were selected a convenience sample of 157 participants (53 males' $33.8 \%$ and 104 females $66.2 \%$ ) among 310 the participants that attending in religious rituals of Mosques in Shiraz, Iran and by Include criteria willingness to participate in the study, attend religious rituals at least three times in a month, not having physical illness, having no emotional and family problems. The mean age of participants was $31.54(\mathrm{SD}=11.09)$, with the range of 18 to 60 years; for men, it was $29.23(\mathrm{SD}=10.36)$ with the range of 18 to 55 years and for women $36.08(\mathrm{SD}=11.09)$ with the range of 20 to 60 years.

The Reasons for Death Fear Scale (RDFS). This scale was developed by Abdel-khalek in 2002 and consists of 18 items. These items have been scaled on a 5-point Likert scale (from $1=$ strongly disagree to $5=$ strongly agree). In a factor analysis, Abdel-khalek (2002) identified 4 reasons for death fear: fear of pain and punishment, fear of losing worldly involvements, religious transgressions and failures, and parting from loved ones. He obtained 0.80 for Cronbach's alpha reliability coefficients of the scale. The validity coefficients of RDFS with the Death Anxiety Scale by Templer (1970), the Death Depression Scale-Revised by Templer, the Death Obsession Scale (Abdel-Khalek, 1998b; Maltby \& Day, 2000), the Arabic Scale of Death Anxiety (AbdelKhalek, 1998), and the Kuwait University Anxiety Scale (Abdel-Khalek, 2000) were statistically significant. The items of the Farsi Reasons for Death Fear Scale were separately translated into Farsi by the authors. The translated versions were then compared to the original text by a language expert, fluent in English, and the words were modified and confirmed as adequately representing the original items. The primary Farsi version was again translated from Farsi into English and compared to the original form, which showed high similarity between the two forms.

\section{Trend of research}

Before submitting questionnaire to participants about the purpose of research and its application in this particular group, the information was provided individually. The participations was also mentioned that they could participate freely and with complete satisfaction. They also provided information on how to respond to each scale, and they were informed that their personal information and scales would be confidential and that the data would be analyzed collectively. To observe ethical standards, after obtaining informed consent from the participants, the questionnaires were completed without lastname to ensure the confidentiality of the information. 
In this study, the data were analyzed using SPSS-23 and applied to the study of psychometric characteristics of the Reasons for Death Fear Scale: 1. A KolmogorovSmirnov test was ran to make ensure of normality of distribution of the data; 2. Exploratory factor analysis with Varimax rotation was performed to identify underlying factors and preliminarily established factorial validity; 3 . Cronbach's alphas were calculated to test internal consistency of the measure; 4 . Finally, convergent and diver- gent validity of the scale were assessed by examining correlations between the Reasons for Death Fear Scale with extracted factors and the factors with each other.

\section{Results}

The mean and standard deviation total score on the RDES was 61.57 and 11.50. The lowest mean item score was 2.37 for item 16 ("Grieving over what one

Table 1. Statistical measures of items of SSES-F $(n=160)$

\begin{tabular}{|c|c|c|c|c|}
\hline \multirow{2}{*}{ Items } & \multicolumn{4}{|c|}{ Factors } \\
\hline & 1 & 2 & 3 & 4 \\
\hline 1. Fear of heavenly punishment & - & - & 0.81 & - \\
\hline 2. Worry about one's offspring & - & - & - & 0.86 \\
\hline 3. Too many sins & - & - & 0.69 & - \\
\hline 4. Life teems with meaningful things & - & - & - & 0.56 \\
\hline 5. Parting from the relatives and beloved & - & 0.48 & - & 0.55 \\
\hline 6. Leaving behind secular pleasures & - & 0.62 & - & - \\
\hline 7. Fear of hell and doomsday & - & - & 0.65 & - \\
\hline $\begin{array}{l}\text { 8. Terribly strenuous moment when the } \\
\text { soul parts from the body }\end{array}$ & 0.69 & - & - & - \\
\hline $\begin{array}{l}\text { 9. Failure to perform religious duties and } \\
\text { obligations }\end{array}$ & - & - & 0.67 & - \\
\hline $\begin{array}{l}\text { 10. Death entails so many vague and } \\
\text { unknown issues }\end{array}$ & 0.61 & - & - & - \\
\hline 11. Element of surprise in death & - & - & - & - \\
\hline 12. Lack of faith & - & 0.45 & 0.48 & 0.45 \\
\hline 13. Grieving of loved ones & 0.79 & 0.44 & - & - \\
\hline 14. Torture of the grave & 0.79 & - & - & - \\
\hline 15. Acute pains associated with dying & - & - & - & - \\
\hline $\begin{array}{l}\text { 16. Grieving over what one will leave } \\
\text { behind, e.g. wealth, valu-ables, etc. }\end{array}$ & - & 0.77 & - & - \\
\hline 17. Loss of self or identity & - & 0.73 & - & - \\
\hline $\begin{array}{l}\text { 18. Death puts an end to one's plans and } \\
\text { objectives Eigenvalues }\end{array}$ & - & 0.71 & - & \\
\hline Eigenvalues & 5.68 & 2.24 & 1.46 & 1.25 \\
\hline$\%$ variance accounted & 31.60 & 12.45 & 8.12 & 6.25 \\
\hline Total of variance & & & $59.43 \%$ & \\
\hline Cronbach's $\alpha$ for each factor & 0.81 & 0.72 & 0.77 & 0.70 \\
\hline
\end{tabular}


Table 2. Convergent validity coefficients of RDFS with other scales

\begin{tabular}{|c|c|}
\hline Scales & RDES \\
\hline Death Depression Scale & 0.34 \\
\hline Death Obsession Scale & 0.37 \\
\hline Death Anxiety Scale & 0.44 \\
\hline
\end{tabular}

Table 3. Convergent validity coefficients of RDFS with other scales

\begin{tabular}{ccccc}
\hline Scale & Factor 1 & Factor 2 & Factor 3 & Factor 4 \\
\hline RDES & 0.34 & 0.78 & 0.21 & 0.38 \\
\hline Factor 1 & - & 0.37 & 0.58 & 0.41 \\
\hline Factor 2 & & - & 0.24 & 0.49 \\
\hline Factor 3 & & & - & 0.39 \\
\hline Factor 4 & & & & - \\
\hline
\end{tabular}

will leave behind, e.g. wealth, valuables, etc."), and the highest mean item score was 4.11 for item 7 ("Fear of hell and doomsday"). A Kolmogorov-Smirnov test was used to ensure that the collected data has a normal distribution. The results $(\mathrm{z}=0.94, \mathrm{P}<0.339)$ showed that the distribution of the collected data is not significantly different from normal. The KMO index (0.83) and Bartlett test of Sphericity $(\mathrm{P}=1029.50, \mathrm{P}<0.001)$, showed that the assumed normal distribution has been observed, and the sample size is sufficient for factor analysis. Table 1 shows the factors for the Reasons for Death Fear Scale.

As shown in Table 1, the four extracted factors explain $59.43 \%$ of the variance of RDFS items. The first factor explained $31.60 \%$ of the variance, and based on item content, it was labeled Fear of Pain and Punishment. Items of the second factor accounted for $12.45 \%$ variance, and this factor was termed Fear of Losing Worldly Pleasure and Investments. The third factor accounted for $8.12 \%$ of the variance and was labeled Fear of not doing Religious Virtues. And, the fourth factor accounted for $6.25 \%$ of the variance and was labeled Fear of Parting from Loved Ones. Thus, the RDFS was found to be a multi-dimensional scale. It should be noted that 2 items (items 5 and 12) have loads on the second factor, but based on items content, item 5 can be placed on the fourth factor, and item 12 has load on the second factor, but it can be loaded on the third factor based on item content in terms of factor loadings higher than 0.40 (Table 1).
The alpha coefficients were 0.86 for the total scale, 0.81 for Fear of Pain and Punishment factor (5 items), 0.72 for Fear of Losing Worldly Pleasure and Investments factor (4 items), 0.77 for Fear of not doing Religious Virtues ( 5 items), and 0.70 for Fear of Parting from Loved Ones. Overall, these results indicate acceptable levels of internal consistency (Table 1).

\section{Discussion}

The scale of RDFS has a good internal consistency and the Cronbach's $\alpha$ coefficient calculated from the sample confirm this finding about of whole scale and the subscales. I doing so, constant factors were extracted from the RDFS and named as fear of pain and punishment, fear of loss of investment and earthly delights, fear of not doing of religious obligations, and fear of being separated from loved ones. Less and more, these factors have cognitive, social and religious aspects. The four extracted factors and their meanings are likely considered as indices of adequacy of items, internal consistency of RDFS and good factorial structure of the scale in measuring one consistent concept (reasons for death fear). Prior studies on the RDFS among Egyptian, Kuwaiti, and Iranian university students also reported good reliability (Abdel-Khalek, 2002A; Aflakseir, 2014).

The principal component analysis showed 4-factor "Fear of Pain and Punishment," "Fear of Losing Worldly Pleasure and Investments," "Fear of not doing Religious Virtues," and "Fear of Parting from Loved Ones". These 
identified components were consistent with the theoretical formulation of the scale and the four components of Abdel-Khalek (2002), and Aflaksair (2014).

One of the basic principles of Islam is to believe in afterlife. In this far live and in the resurrection day the soul and body would be revived, and after a final trade-off, reward or punish (paradise or hell) would be become every man eternal destiny. Afterlife is immortal and infinite live of man. This life is very certain and after being buried in the ground would began. This ground, depend on actions done in the world, would end up somewhere near the heaven or somewhere in deep valleys of hell. In the latter one, grave suffering, i.e. torture of grave would occur. In the Islam religion, Muslims believe that the God would create life and death. They also believe that death is visiting God and is a transition from earth mortal life to the eternal life in heaven or hell. Every true Muslim believes that God has determined the exact time of death for everyone. Nobody, however, knows the time (AlSabwah \& Abdel-Khalek, 2006).

With the exception of Abdel-Khalek (2002A), and Aflaksier (2014) works there is no empirical evidence directly assigned to the research question 'why we fear of death?' Thus, this study was succeeding in accomplishing the research main goal (construct validity).

There are significant positive correlations of RDFS to the other scales that indicate its convergent validity. These results are consistent with the results of Abdel-Khalek (2002A), Abdel-Khalek (2004), Aflakseir (2014), and Ayyad (2013) who found RDFS to be significantly and positively correlated to the Death Anxiety Scale, Death Depression Scale, Death Distress Scale and Death Obsession Scale.

Based on voluntarily selection of people participated in religious rituals in Shiraz, Iran, 18 items of the Reasons for Death Fear Scale (RDFS) were analyzed after the initial translation and several times modification of the items for their contents (exploratory factor analysis). Therefore, we certainly concluded that the RDFS appropriately represents the participants' views in response to the question, 'why we fear of death?' Thus, the generalizability of the current finding to other samples similar to Iranians, show in a high extent that what are the possible similarities between the current findings and other participants from other cultures, places, languages, and religious orientations for reasons of linguistic commonalities and being Muslim. In other words, their common major meaning in the country is Persian language and they are Muslims just like the other adjacent countries, especially the Arab ones (Table $2 \& 3$ ).

All of religions have paid attention to the issue fear of death across the world; for instance, in a part of Christians' teachings it has come: everybody in the world will face death in the last moments of their lives, and the moment is terrifying and fearful (Brantl, 1961). Islam is not an exception. In this religion, the issues death and fear of it are viewed intrinsic and, of course, considerable; thus, in Muslims' holy book and elderlies' speeches of this religion, the issue is preceded a lot. According to various verses of Qur'an about death being unavoidable, pains related to death moment and dying, auditing to sins in another world, and time and place of death being unknown, it is inferred that unawareness and unrecognition of nature of death, attachment to the world, fear of death pains, perpetrated sins, and fear of the auditing are some main reasons of fear of death.

Beg and Zilli (1982) have stated that "the pains and agonies of the grave are many and unknown" (p. 122). In the religious Islam, it is true that these pains and agonies are many, but they are not unknown, inasmuch as many saying Ahadeath of the prophet of Islam elucidate the different forms of Azab Al-Qabr. Thus, it is predictable that item 2 (i.e. "Worry about one's offspring"), item 1 (i.e. "fear of heavenly punishment") and Items 14 and 15 (i.e. "Torture of the grave", " Acute pains associated with dying") had primary, second and third highest ranks among the items of the RDFS, respectively.

\section{Conclusion}

There are some limitations in this research. First, it is important to note that the research has been done on women and men attending in religious rituals (e.g. mosques and prays) and the generalization of the results to other populations should be done cautionary. Lack of test-retest reliability coefficient of RDFS is another limitation making hard the generalization to other samples with age, educational, occupational, and ethnic characteristics. The current findings are particularly related to Iranian Muslim papulation, thus, we recommend studying the scale in other cultures (western and nonwestern ones). It is suggested that researcher's evaluate this scale in different age groups and populations. Another suggestion is to use the retest reliability method to investigation this scale over time. 


\section{Ethical Considerations}

\section{Compliance with ethical guidelines}

All ethical principles were considered in this article. The participants were informed about the purpose of the research and its implementation stages; they were also assured about the confidentiality of their information; Moreover, They were allowed to leave the study whenever they wish, and if desired, the results of the research would be available to them.

\section{Funding}

This research did not receive any specific grant from funding agencies in the public, commercial, or not-forprofit sectors.

\section{Authors' contributions}

All authors contributed equally in preparing all parts of the research.

\section{Conflict of interest}

The authors declared no conflict of interest.

\section{References}

Abdel-Khalek, A. M. (2004). A general factor of death distress in seven clinical and non-clinical groups. Death Studies, 28, 889898. [DOI: 10.1080/07481180490491040]

Abdel-Khalek, A. (2005). Happiness and death distress: two separate factors. Death Studies, 29, 949-58. [DOI: 10.1080/07481180500299394]

Abdel-Khalek, A. M. (2002A). Why do we fear death? The construction and validation of the Reasons for Death Fear Scale. Death Studies, 26, 8, 669-80. [DOI: $10.1080 / 07481180290088365]$

Abdel-Khalek, A. (2002B). Death obsession in Egyptian samples: differences among people with anxiety disorders, schizophrenia, addictions and normal. Death Studies, 26, 413-426. [DOI: 10.1080/07481180290087384]

Abdel-Khalek, A. M. (1998). The structure and measurement of death obsession. Personality and Individual Differences, 24(2), $159-65$.

Abdel-Khalek, A., Al-Arja, N. S., \& Abdalla, T. (2006). Death Obsession in Palestinians. Death Studies, 30, 3, 203-15. [DOI: 10.1080/07481180500493302]
Abdel-Khalek A. M., \& Tomass-Sabado, J. (2005). Anxiety and death anxiety in Egyptian and Spanish nursing students. Death Studies, 29, 157-69. [DOI: 10.1080/07481180590906174]

Abu Hasheesh, M. O., Al-Sayed AboZeid, S., Goda El-Zaid, S., \& Alhujaili, A. D. (2013). Nurses' characteristics and their Attitudes toward Death and Caring for Dying Patientsin a Public Hospital in Jordan. Health Science Journal, 7(4), 384-394.

Afkakseir, A. A. (2014). Reasons for death fear, religiosity and anxiety among students of University of Shiraz. Journal Mod Psychological Research, 9, 30-43.

Almostadi, D. A. (2012). The Relationship between Death Depression and Death Anxiety among Cancer Patients in Saudi Arabia. Graduate School Theses and Dissertations. U.S.: University of South Florida.

Al-Sabwah, M. N., \& Abdel-khalek, A. M. (2005-2006). Fouryear cross-sectional comparison of death distress among nursing college students. Omega: Journal of Death and Dying, 52 (3), 237-48. [DOI: 10.2190/5LJ1-BF5B-62QP-1YC9]

Alvarado K. A., Templer D. I., Bresler, C., \& Thomas-Dobson, S. (1995). The relationship of religious variables to death depression and death anxiety. Journal of Clinical Psychology, 51, $2,202-4$.

Ayyad, F. (2013). Death distress among two samples of lower and higher stress in health care professionals. Psychological Reports, 113(1), 332-21.

Becker, E. (1973). The Denial of Death. New York: Free Press.

Beg, M. A., \& Zilli, A. S. (1982). A study of the relationship of death anxiety and religious faith $t$ age differential. Psychologia, $25,121-5$.

Brantl, G. (1961). Catholicism. New York: Braziller.

Chen, Y. C., Benk, B. L., \& Lewis, J. (2006). Differential dimension of death anxiety in nursing students with and without nursing experience. Death Studies, 30, 919-29. [DOI: $10.1080 / 07481180600925351]$

Choron, J. (1974). Death and modern man. New York: Macmillan.

Campbellm, G. D. (2013). Exit strategy a textbook on death and dying. New York: New Paltz.

Dezutter, J., Luyckx, K., \& Hutsebaut, D. (2009). Are you afraid to die? Religion and death attitudes in an adolescent sample. Journal of Psychology and Theology, 37, 163-73. [DOI: $10.1080 / 07481180802494289]$

Ellis, L., \& Wahab, E. A. (2013). Religiosity and fear of feath: A theory-oriented review of the empirical literature. Review of Religious Research, 55, 149-89. [DOI: 10.1007/s13644-0120064-3]

Kastenbaum, R., \& Aisenberg, R. (1972). The psychology of death. New York: Springer.

Florian, V., \& Mikulincer, M. (1993). The impact of death-risk experiences and religiosity on the fear of personal death: The case of Israeli soldiers in Lebanon. Omega: Journal of Death and Dying, 26, 101-11. [DOI: 10.2190/5FDN-UQ53-DAR8-U283] 
Hoelter, J, W., \& Hoelter, J. A. (1978). “The relationship between fear of death and anxiety." Journal of Psychology, 99, 225-6. [DOI: 10.1080/00223980.1978.9921462]

Maltby, J., \& Day, L. (2000). Religious orientation and death obsession. Journal of Genetic Psychology, 16, 122-124. [DOI: 10.1080/00221320009596699]

Moore, C., \& Williamson, J. (2003). The universal fear of death and the cultural response. In Handbook of death \& dying. Thousand Oaks, CA: Sage Publications.

Neimeyer, R., Wittkowski, J., \& Moser, R. P. (2004). Psychological research on death attitudes: An overview and evaluation Death Studies, 28, 309-40. [DOI: 10.1080/07481180490432324]

Paul, M. (2012). Fear of death. The Huffington post. Retrieved from http://www.huffingtonpost.com/margaret-paul-phd/fear-of death_b_1404365.html.

Power, T. L., \& Smith, S. M. (2008). Predictors of fear of death and self-mortality: An Atlantic Canadian perspective. Death Studies, 32, 253-72. [DOI: 10.1080/07481180701880935]

Rajabi, Gh., \& Naderi Nobandegani, Z. (2018). Death obsession, death anxiety, and depression as predictors of death depression among nurses. Jentashapir Journal Health Research (In press).

Rajabi, Gh. (2009). The psychometric properties of death obsession scale in freshman undergraduate students. Journal of Applied Sciences, 9, 360-5. [DOI: 10.3923/jas.2009.360.365]

Rajabi, Gh., \& Bahrani, M. (2002). Item factor analysis of the Death Anxiety Scale. Iranian Association Psychology, 20, 5, 331-44.

Rajabi, Gh., Begdeli, Z., \& Naderi Nobandegani, Z. (2015). Psychometric properties of the Persian version of Death Depression Scale among nurses. Death Studies, 39, 342-6. [DOI: 10.1080/07481187.2014.951495]

Roshdieh, S., Templer, D. I., \& Cannon, W. G. (1999). The relationship of death anxiety and death depression to religion and civilian war-related experiences in Iranians. Omega: Journal of Death and Dying, 38, 201-10. [DOI: 10.2190/UB6TQF51-AF5J-MLCD]

Templer, D. I. (1970). The construction and validation of a Death Anxiety Scale. Journal of General Psychology, 82, 165-77. [DOI: 10.1080/00221309.1970.9920634]

Wong, P. T. P. Meaning management theory and death acceptance. In Tomer, A., Eliason, G. T., \& Wong, P. T. P. (2008) Existential and spiritual issues in death attitudes. New York: Lawrence Erlbaum Associates. 